\title{
The effects of levosimendan use on high-sensitivity C-reactive protein in patients with decompensated heart failure
}

Hasan Korkmaz ${ }^{1}$ Mücahid Yilmaz²

\begin{abstract}
${ }^{1}$ Department of Cardiology, Firat University Hospital, Elazığ, Turkey 2Department of Cardiology, T.C Health Sciences University, Elazığ Fethi Sekin City Hospital, Elazığ, Turkey
\end{abstract}

Submitted: 6 May 2019

Accepted: 22 June 2019

Arch Med Sci Atheroscler Dis 2019; 4: e174-e179

DOI: https://doi.org/10.5114/amsad.2019.86803

Copyright @ 2019 Termedia \& Banach

\begin{abstract}
Introduction: The present study was intended to investigate the effect of levosimendan on high-sensitivity C-reactive protein (hsCRP) levels in hospitalized patients with decompensated heart failure.

Material and methods: The present study was designed as a prospective controlled clinical trial. A total of 50 patients with decompensated heart failure who were admitted to our hospital were included in the present study. Patients with stage III-IV heart failure based on the New York Heart Association, with systolic blood pressure $>100 \mathrm{~mm} \mathrm{Hg}$ and with left ventricular ejection fraction of $<35 \%$, were selected for the study population. The selected patients were divided into groups, levosimendan and furosemide. Results: There was no significant difference between the groups based on demographics, basal echocardiographic and basal laboratory data. No difference was determined in basal hsCRP $(\mathrm{mg} / \mathrm{l})$ levels between the group admitted levosimendan infusion and the furosemide group $(9.99 \pm 6.2,9.23 \pm 6.4$, $p=0.66)$. However, the hsCRP levels measured at the $24^{\text {th }} \mathrm{h}(38.34 \pm 32.1$ vs. $12.97 \pm 12.3, p<0.001)$, the $48^{\text {th }} \mathrm{h}(31.13 \pm 29.9$ vs. $12.44 \pm 10.1, p=0.003)$ and the $72^{\text {nd }} h(27.41 \pm 26.9$ vs. $9.89 \pm 8.4, p=0.002)$ were significantly higher in the levosimendan infusion group than the furosemide group.

Conclusions: It was found that hsCRP levels were significantly higher in the levosimendan infusion group than the furosemide group. Such an outcome could be related to myocyte injury and/or the amplification of the inflammatory response due to levosimendan.
\end{abstract}

Key words: heart failure, levosimendan, high-sensitivity C-reactive protein.

\section{Introduction}

The decrease of cardiac stroke volume to the level that the metabolic needs of the tissues cannot be met causes the symptoms of heart failure. Heart failure often occurs in the course of different cardiovascular diseases, at the final stage of these diseases, and is considered to be an important cause of mortality and morbidity [1]. Despite the improvements in treatment, the 5-year mortality rate is approximately $60 \%$ and this rate is higher than the mortality rate of most malignancies [2].

Inotropic agents are drugs that are used in the treatment of acute heart failure, where systolic dysfunction is accompanied by peripheral hypoper-

\author{
Corresponding author: \\ Hasan Korkmaz MD \\ Department of Cardiology \\ Firat University \\ Hospital \\ Elazığ, Turkey \\ E-mail: hkorkmaz23@ \\ hotmail.com
}


fusion or hypotension [3]. It was reported that the main mechanism of action of levosimendan in increasing myocardial contractility was based on increasing the susceptibility of cardiac troponin- $C$ to cytoplasmic calcium [4]. Recent studies indicated that C-reactive protein (CRP) and high-sensitivity C-reactive protein (hsCRP) were risk factors for heart failure [5, 6]. Moreover, studies suggested that hsCRP could be accepted as an independent indicator of mortality in patients with heart failure [7]. Higher CRP levels are associated with more severe heart failure. The relationship between CRP and heart failure was explained with the high filling pressures of the left ventricle [5].

It is unclear how levosimendan infusion affects serum hsCRP levels. The present study aimed to investigate whether levosimendan use affects hsCRP levels in hospitalized patients with decompensated heart failure and in patients with heart failure under routine treatment.

\section{Material and methods}

The present study was designed as a prospective controlled clinical trial. A total of 50 patients with decompensated heart failure, who applied to the emergency department in our hospital and were admitted to the coronary intensive care unit, were included in the present study. Patients with stage III-IV heart failure based on the New York Heart Association (NYHA), with systolic blood pressure $>100 \mathrm{~mm} \mathrm{Hg}$ and with left ventricular ejection fraction of $<35 \%$, were selected for the study population. Patients who presented to the emergency department due to decompensated heart failure were admitted to the coronary intensive care unit and they were administered nasal oxygen, their venous blood was taken, and echocardiography was conducted on these patients. The patients were randomized to levosimendan $(n=25)$ and furosemide groups $(n=25)$. The patients in the levosimendan group received levosimendan infusion with a maintenance dose of $0.1 \mu \mathrm{g} / \mathrm{kg} / \mathrm{min}(24 \mathrm{~h})$. The dose was halved when hypotension developed in patients. The furosemide group received a 100 to $160 \mathrm{mg}$ daily dose of furosemide intravenous infusion. The highest tolerable doses of angiotensin converting enzyme inhibitors (ACE), $\beta$-blockers, and low-dose spironolactone therapy were administered to each patient due to their clinical status. Optimal medical treatments were planned for all patients.

\section{Transthoracic echocardiogram (ECO)}

M-mode and 2D ECO were performed based on the American Society of Echocardiography criteria using 3.25 probes in a Vivid 3 ECO echocardiography device on the left side in the decubitus position.
Parasternal short-long axial images with standard echocardiographic positions and apical 4-space images were used in the measurements and these images were used to obtain the ejection fraction (EF) measurements and left ventricular systolic-diastolic diameters by the Simpson method. Each measurement was repeated twice, and the mean values of the measurements were taken into consideration. For standardization purposes, all measurements were conducted by the same individual.

\section{Blood measurements}

Ten $\mathrm{ml}$ basal blood samples, required to measure the hsCRP content and control parametric values, such as electrolytes, CBC, liver (AST, ALT) and kidney functions (urea, creatinine), were drawn from both groups at the $24^{\text {th }}, 48^{\text {th }}$ and $72^{\text {nd }} \mathrm{h}$ using a cannula from the antecubital vein. The measurements were conducted with an OLYMPUS 2700 auto-analyzer and the results were recorded separately for each patient.

\section{Ethics}

The study was initiated after receiving the approval of the local ethics committee and written informed consents forms were received from all patients included in the present study. The study was conducted in accordance with the Declaration of Helsinki.

\section{Exclusion criteria}

Patients younger than eighteen with restrictive or hypertrophic cardiomyopathy, uncorrected valve stenosis, infection, hypotension (systolic and diastolic blood pressure $<100 / 60 \mathrm{~mm} \mathrm{Hg}$ ), EF over $35 \%$, severe hepatic impairment, severe renal failure (creatinine levels > $3.0 \mathrm{~g} / \mathrm{dl}$ ) and patients with acute coronary syndrome, uncontrolled hypertension, or chronic obstructive pulmonary disease (COPD) were not included in the study. Furthermore, after being randomized to groups, patients who required medication or device support were excluded from the study.

\section{Statistical analysis}

Statistical analyses were conducted with SPSS software for Windows version 17.0 (SPSS Inc., Chicago, USA). Continuous variables were expressed as mean \pm standard deviation and the categorical variables were expressed as count and percentage. In order to determine whether the variable data exhibited normal distribution, the Kolmogorov-Smirnov test was used. The $\chi^{2}$ test was used for qualitative variables and Student's $t$ test was used for quantitative variables. A $p$-value $<0.05$ was considered significant. 


\section{Results}

No significant difference was found between the levosimendan and furosemide treatment groups based on demographic, baseline echocardiographic and basal laboratory data (Table I).

Additionally, there was no difference in basal hsCRP ( $\mathrm{mg} / \mathrm{l})$ levels between the levosimendan infusion and furosemide groups (9.99 $\pm 6.2,9.23 \pm 6.4$, $p=0.66)$. However, the hs-CRP levels measured at the $24^{\text {th }} \mathrm{h}(38.34 \pm 32.1$ vs. $12.97 \pm 12.3, p<0.001)$, the $48^{\text {th }} \mathrm{h}(31.13 \pm 29.9$ vs. $12.44 \pm 10.1, p=0.003)$ and the $72^{\text {nd }} h(27.41 \pm 26.9$ vs. $9.89 \pm 8.4, p=0.002)$ were significantly higher in the levosimendan infusion group than the furosemide group (Table II, Figure 1).

\section{Discussion}

Intravenous positive inotropic agents play an important role in short-term treatment of decom-

Table I. Baseline characteristics in the levosimendan-treated and furosemide groups

\begin{tabular}{|c|c|c|c|}
\hline Parameter & Levosimendan & Furosemide & $P$-value \\
\hline Age [years] & $67 \pm 10$ & $69 \pm 9$ & 0.674 \\
\hline Sex [male] & 13 & 12 & NS \\
\hline Arterial blood pressure systole [mm Hg] & $121 \pm 16$ & $118 \pm 14$ & 0.467 \\
\hline Arterial blood pressure diastole [mm Hg] & $74 \pm 9$ & $70 \pm 9$ & 0.159 \\
\hline Heart rate [beats/min] & $78 \pm 11$ & $79 \pm 14$ & 0.753 \\
\hline Height $[\mathrm{cm}]$ & $167 \pm 7$ & $166 \pm 7$ & 0.513 \\
\hline Weight $[\mathrm{kg}]$ & $70 \pm 8$ & $69 \pm 10$ & 0.730 \\
\hline Body mass index $\left[\mathrm{kg} / \mathrm{m}^{2}\right]$ & $25 \pm 2$ & $25 \pm 3$ & 0.388 \\
\hline Atrial fibrillation, $n(\%)$ & $8(32)$ & $9(36)$ & NS \\
\hline Diabetes mellitus, $n$ (\%) & $4(16)$ & $3(12)$ & NS \\
\hline Hypertension, $n$ (\%) & $7(28)$ & $8(32)$ & NS \\
\hline COPD, $n(\%)$ & $4(16)$ & $3(12)$ & NS \\
\hline Disease duration [months] & $57 \pm 43$ & $58 \pm 37$ & NS \\
\hline Ischemic/non-ischemic, $n$ & $10 / 15$ & $9 / 16$ & NS \\
\hline History of myocardial infarction, $n(\%)$ & $4(16)$ & $5(20)$ & NS \\
\hline Bypass history, $n(\%)$ & $1(4)$ & $2(8)$ & NS \\
\hline Stent history, $n$ (\%) & $2(8)$ & $4(16)$ & NS \\
\hline Urea [mg/dl] & $49 \pm 14$ & $48 \pm 18$ & 0.369 \\
\hline Creatinine $[\mathrm{mg} / \mathrm{dl}]$ & $0.98 \pm 0.28$ & $0.82 \pm 0.29$ & 0.555 \\
\hline $\mathrm{AST}[\mathrm{U} / \mathrm{I}]$ & $25 \pm 7$ & $26 \pm 14$ & 0.782 \\
\hline $\mathrm{ALT}[\mathrm{U} / \mathrm{I}]$ & $26 \pm 6$ & $31 \pm 7$ & 0.286 \\
\hline Glucose $[\mathrm{mg} / \mathrm{dl}]$ & $118 \pm 48$ & $121 \pm 74$ & 0.929 \\
\hline White blood cells $\left[\times 10^{9} / I\right]$ & $7418 \pm 1261$ & $6692 \pm 132$ & 0.802 \\
\hline Hematocrit (\%) & $41 \pm 4$ & $42 \pm 5$ & 0.425 \\
\hline Platelet $\left[\times 10^{9} / 1\right]$ & $207 \pm 52$ & $178 \pm 43$ & 0.293 \\
\hline $\mathrm{EF}(\%)$ & $27 \pm 5$ & $25 \pm 5$ & 0.849 \\
\hline Left ventricular diastolic diameter [mm] & $59 \pm 9$ & $57 \pm 16$ & 0.511 \\
\hline Left ventricular systolic diameter [mm] & $51 \pm 10$ & $48 \pm 16$ & 0.453 \\
\hline Potassium [mEq/l] & $4.2 \pm 0.53$ & $4 \pm 0.41$ & 0.257 \\
\hline Sodium $[\mathrm{mEq} / \mathrm{l}]$ & $139 \pm 3$ & $139 \pm 3$ & 0.704 \\
\hline
\end{tabular}

NS - non-significant, COPD - chronic obstructive pulmonary disease. 
Table II. Changes in hsCRP values of levosimendan and furosemide groups

\begin{tabular}{|lcccc|}
\hline Variable & \multicolumn{4}{c|}{ HsCRP $[\mathbf{m g} / \mathbf{l}]$} \\
\cline { 2 - 5 } & Basal & $\mathbf{2 4}^{\text {th }} \mathbf{h}$ & $\mathbf{4 8}^{\text {th }} \mathbf{h}$ & $\mathbf{7 2}^{\text {nd }} \mathbf{h}$ \\
\hline Levosimendan & $9.99 \pm 6.2$ & $38.34 \pm 32.1$ & $31.13 \pm 29.9$ & $27.41 \pm 26.9$ \\
\hline Furosemide & $9.23 \pm 6.4$ & $12.97 \pm 12.3$ & $12.44 \pm 10.1$ & $9.89 \pm 8.4$ \\
\hline$P$-value & 0.659 & $<0.001$ & 0.003 & 0.002 \\
\hline
\end{tabular}

pensated heart failure due to left ventricular systolic dysfunction $[8,9]$. However, there exists no ideal inotropic agent that is both effective and has a low side effect profile. Despite the provision of rapid symptomatic improvement, these agents could lead to mortality in the long term [8]. It was also reported that increased intracellular CAMP and $\mathrm{Ca}+$ concentration due to the use of positive inotropic was cardiotoxic [10]. Such condition causes a further increase in the energy requirement of the cell and the oxygen consumption of the myocardium [10]. It was reported that the main action mechanism of levosimendan in increasing myocardial contractility was based on the increase in the susceptibility of cardiac troponin-C to cytoplasmic calcium [4]. Such interaction is assumed to provide the inotropic effect through stabilizing the calcium-induced structural changes in tropomyosin and strengthening the actin-myosin cross-bridges. The intracellular calcium level does not increase during this inotropic effect and this is the most significant characteristic; thus, significant side effects such as cardiac myocyte dysfunction and arrhythmia due to intracellular calcium increase caused by adrenergic inotropes are considered to be prevented. It was suggested that sensitization due to levosimendan was dependent on the calcium concentration; hence the contractile elements had inotropic effects in systole, whereas the diastolic relaxation was not impaired since the diastole calcium concentration was low [11].

C-reactive protein is a pentameric acute phase protein produced in the liver [12]. It is also mentioned that CRP could additionally be synthesized extrahepatically by neurons, atherosclerotic plaques, monocytes and lymphocytes [13]. Although it is not fully acknowledged how the synthesis is controlled in these regions, these synthesis regions have an effect on plasma CRP levels. Various studies have concluded that CRP predicts the risk of future cardiovascular diseases independently of the known risk factors in healthy individuals [14]. Although it is at a low level, the inflammatory reaction could be responsible for disease development and poor prognosis in patients with coronary artery disease, stroke, peripheral vascular disease and diabetes, and moreover, it was indicated that a certain benefit could be

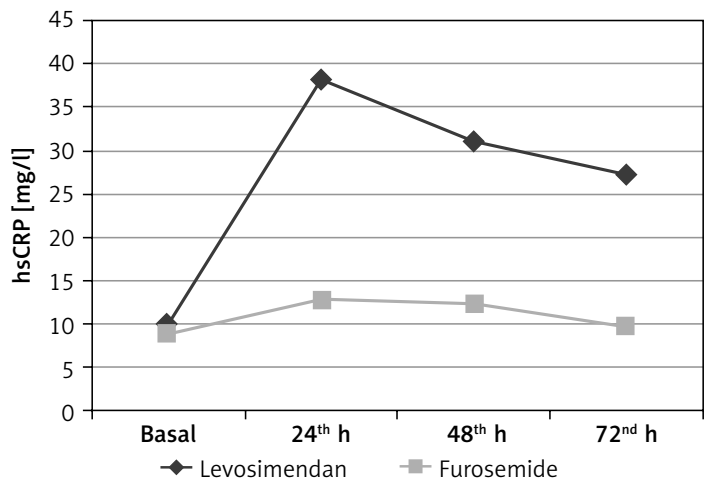

Figure 1. Change in hsCRP levels based on treatment groups

obtained with drugs that have anti-inflammatory effects such as statins. Due to the presence of inflammatory cytokines in patients with heart failure, the question as to whether these agents have effects on the development and progression of heart failure became a focus of interest. According to the cytokine hypothesis, heart failure partially progresses due to the cardiac and systemic effects of these cytokines. It was not fully explained whether CRP was the sole indicator of an underlying inflammatory response and tissue damage, or directly contributed to the development of the immune response, leading to further tissue damage that accelerated the advance towards heart failure. Studies indicated that higher hsCRP levels were associated with poorer prognoses even after the planning of treatment based on other risk factors in cardiovascular diseases that were not associated with myocardial necrosis. Furthermore, hsCRP determines the outcome independently of the infarction size or recurrent infarction in diseases associated with myocardial necrosis. Such findings supported the hypothesis that CRP contributed directly to disease progression, possibly through amplification of the existing inflammatory reaction. Various studies have reported that inflammatory markers were elevated in patients with heart failure. For instance, tumor necrosis factor $\alpha$ (TNF- $\alpha)$, soluble TNF receptor 1 and 2 or interleukin 6 (IL-6) increased in patients with heart failure and were associated with the severity of the heart failure and the increased cardiovascular mortality in follow-up $[15,16]$. Several 
studies focusing on this topic have indicated that high levels of hsCRP had a prognostic value beyond the plasma B-type natriuretic peptide (BNP) values [17-19]. In the study SURVIVE, BNP values decreased in the early periods of levosimendan infusion, and this finding was not proven to have a positive effect on 180-day mortality [20]. Another study suggested that high hsCRP values in heart failure patients resulted in twice the re-hospitalization and death risk [21].

The Val-HeFT study was considered the most prominent study that presented the effects of hsCRP on morbidity and mortality in heart failure. In the Val-HeFT study, it was observed that the patient population of 4000 with heart failure had an average hsCRP of $3.23 \mathrm{mg} / \mathrm{l}$ and the patients with higher hsCRP exhibited more severe heart failure symptoms (lower LVEF, higher NYHA and worse quality of life) and worse neurohormonal profiles (higher BNP, norepinephrine and aldosterone levels). Additionally, the study reported that the prognostic significance of hsCRP was independent of BNP and the etiology of heart failure [22]. In the literature, we did not find a study that aimed to investigate the effects of levosimendan on hsCRP. One study included hsCRP variations in the findings, although it did not aim to report the correlation between levosimendan and hsCRP. In this retrospective study, the effects of levosimendan, dobutamine and vasodilator treatment on ongoing myocardial injury in acute decompensated heart failure were compared. In the results section, it was reported that hsCRP increased from $43 \mathrm{ng} / \mathrm{ml}$ to $67 \mathrm{ng} / \mathrm{ml}$ at the $48^{\text {th }} \mathrm{h}$ subsequent to levosimendan administration [23].

In the present study, it was observed that hsCRP levels were higher at the $24^{\text {th }}, 48^{\text {th }}$ and $72^{\text {nd }}$ $\mathrm{h}$ in the group of patients who received levosimendan infusion. This finding could be explained by the fact that the effectiveness of levosimendan lasted longer than $24 \mathrm{~h}$ and its pharmacological effects continued up to 1 week after the discontinuation of the drug [24]. The increase in hsCRP levels, which is an acute phase reactant, subsequent to levosimendan infusion when compared to the control group could be interpreted as an increased myocyte damage and/or inflammatory response. Nevertheless, accompanying analyses of TNF- $\alpha$, soluble TNF receptor 1 and 2 and inflammatory markers such as IL-6 could help to report clearer findings. Given the studies that suggested adverse effects of hsCRP elevation on mortality, it becomes evident that the potential associations between the levosimendan infusion-induced systemic inflammatory response and its adverse effects on long-term mortality deserve a greater focus of interest in the cardiology community.

The main limitation to the study was the low number of cases in both groups. Other limitations are the lack of investigation for inflammatory cytokines such as TNF- $\alpha$, IL- 6 , or IL- $1 \beta$ during the follow-up of patients and the lack of long-term follow-up of the patients.

In conclusion, the present study revealed that hsCRP levels measured in the levosimendan infusion group were high during the treatment of decompensated heart failure. The obtained findings suggested that levosimendan infusion could lead to possible cardiac myocyte damage and/or a possible increase in the systemic inflammatory response. A further study that focuses on the effects of levosimendan on long-term mortality could facilitate an answer to certain other questions once hsCRP levels are measured along with the measurements of extensive inflammatory markers.

\section{Conflict of interest}

The authors declare no conflict of interest.

\section{References}

1. Cleland JG, Khand A, Clark A. The heart failure epidemic: exactly how big is it? Eur Heart J 2001; 22: 623-6.

2. Stewart S. Prognosis of patients with heart failure compared with common types of cancer. Heart Fail Monit 2003; 3: 87-94.

3. Nieminen MS, Böhm M, Cowie MR, et al. Executive summary of the guidelines on the diagnosis and treatment of acute heart failure: the Task Force on Acute Heart Failure of the European Society of Cardiology. Eur Heart J 2005; 26: 384-416.

4. Parissis JT, Filippatos G, Farmakis D, Adamopoulos S, Paraskevaidis I, Kremastinos D. Levosimendan for the treatment of acute heart failure syndromes. Expert Opin Pharmacother 2005; 6: 2741-51.

5. Williams ES, Shah SJ, Ali S, Na BY, Schiller NB, Whooley MA. C-reactive protein, diastolic dysfunction, and risk of heart failure in patients with coronary disease: Heart and Soul Study. Eur J Heart Fail 2008; 10: 63-9.

6. Kang S, Fan LY, Chen M, Li J, Liu ZM. Relationship of high-sensitivity C-reactive protein concentrations and systolic heart failure. Curr Vasc Pharmacol 2017; 15: 390-6.

7. Jackson CE, Haig C, Welsh P, et al. The incremental prognostic and clinical value of multiple novel biomarkers in heart failure. Eur J Heart Fail 2016; 18: 1491-8.

8. Felker GM, O'Connor CM. Inotropic therapy for heart failure: an evidence-based approach. Am Heart J 2001; 142: 393-401.

9. Cohn JN, Goldstein SO, Greenberg BH, et al. A dose dependent increase in mortality with vesnari none among patients with severe heart failure. N Engl I Med 1998; 339: 1810-6.

10. Slawsky MT, Colucci WS, Gottlieb SS, et al. Acute hemodynamic and clinical effects of levosimendan in patients with severe heart failure. Study Investigators. Circulation 2000; 102: 2222-7.

11. Sorsa T, Heikkinen S, Abbott MB, et al. Binding of levosimendan, a calcium sensitizer, to cardiac troponin C. J Biol Chem 2001; 276: 9337-43.

12. Black S, Kushner I, Samols D. C-reactive protein. J Biol Chem 2004; 279: 48487-90. 
13. Kuta AE, Baum LL. C-reactive protein is produced by a small number of normal human peripheral blood lymphocytes. J Exp Med 1986; 164: 321-6.

14. Deveraj S, Kumaresan PR, Jialal I. Effect of C-reactive protein on chemokine expression in human aortic endothelial cells. J Mol Cell Cardiol 2004; 36: 405-10.

15. Tsutamato T, Hisanaga T, Wada A. Interlukin-6 in the peripheral circulation increases with the severity of heart failure, and the high plasma level of interleukin- 6 is an important prognostic predictor in patients with congestive heart failure. J Am Coll Cardiol 1998; 31: 391-8.

16. Rauchhaus M, Doehner W, Francis DP, Davos C, Kemp M Plasma cytokin parameters and mortality in patients with chronic heart failure. Circulation 2000; 102: 3060-7.

17. Windram JD, Loh PH, Rigby AS, Hanning I, Clark AL, Cleland JG. Relationship of high-sensivity c-reaktif protein to prognosis and other prognosis marker in outpatients with heart failure. Am Heart J 2007; 153: 1048-55.

18. Tang WH, Shrestha K, Van Lente F, et al. Usefulness of $\mathrm{C}$-reactive protein and left ventricular diastolic performance for prognosis in patients with left ventricular systolic heart failure. Am J Cardiol 2008; 101: 370-3.

19. Ishikawa C, Tsutamoto T, Fujii M, Sakai H, Tanaka T, Horie M. Prediction of mortality by high sensitivity C-reactive protein and brain natriuretic peptide in patients with dilated cardiomyopaty. Circ J 2006; 70: 857-63.

20. Cohen-Solal A, Logeart D, Huang B, Cai D, Nieminen MS, Mebazaa A; SURVIVE Investigators. Lowered B-type natriuretic peptide in response to levosimendan or dobutamine treatment is associated with improved survival in patients with severe acutely decompensated heart failure. J Am Coll Cardiol 2009; 53: 2343-8.

21. Yin WH, Chen JW, Feng AN, Lin SJ, Young S. Multimarker approach to risk stratication among patients with advanced chronic heart failure. Clin Cardiol 2007; 30: 397-402.

22. Anand IS, Latini R, Florea VG, et al. C-reactive protein in heart failure. Prognostic value and effect of valsartan. Circulation 2005; 112: 1428-34.

23. Gencer E, Doğan V, Öztürk MT, Nadir A, Musmul A, Cavuşoğlu Y. Comparison of the effects of levosimendan dobutamine and vasodilator therapy on ongoing myocardial injury in acute decompensated heart failure. J Cardiovasc Pharmacol Ther 2017; 22: 153-8.

24. Kivikko M, Antila S, Eha J, Lehtonen L, Pentikäinen PJ. Pharmacokinetics of levosimendan and its metabolites during and after a 24-hour continuous infusion in patients with severe heart failure. Int I Clin Pharmacol Ther 2002; 40: 465-71. 